\title{
O plástico na agricultura
}

\section{A plasticultura acelera o desenvolvimento agrícola *}

O uso de plásticos na agricultura (Plasticultura) teve o seu início nos anos quarenta mas foi nas últimas duas décadas que conheceu um desenvolvimento tão notável que não será exagerado classificá-lo de espectacular. Em França, por exemplo, entre 1957 e 1975, a tonelagem anual de plásticos utilizados na agricultura cresceu 600 vezes para a plasticultura propriamente dita e 800 vezes para a plasticultura alargada. $\mathrm{O}$ consumo atingiu, respectivamente, 60000 e 150000 toneladas no último ano desse período- ${ }^{1}$ ).

Em Portugal, não conhecemos dados estatísticos oficiais que nos permitam traçar um paralelo com a situação francesa, mas, graças a trabalhos executados a nível da CNP (2) podemos apresentar valores relativos às épocas de 76/77 e 79/80, os quais confirmamos contra números registados pela APPA (3) - QUADRO I - e comparamos com os valores correspondentes em França e no Mundo (4) - QUADRO II. Finalmente apresentamos a evolução da situação em França entre 1975 e 1977 - QUADRO III.

\section{AS DIVERSAS TÉCNICÁS}

Os valores observados indicam ser ainda bastante reduzido o consumo de plásticos na agricultura em Portugal, relativamente a países estrangeiros, embora não tenhamos dados relativoss a 1981. Mas, para além do atraso com que se costumam, no nosso país, adoptar as novas tecnologias, há talvez outros factores limitativos do desenvolvimento de algumas técnicas de plasticultura.

\section{QUADRO I}

EVOLUÇÃO DA PLASTICULTURA EM PORTUGAL ENTRE 1976-77 E 1979-80

\begin{tabular}{lrrrrrr}
\hline \multirow{2}{*}{ TÉCNICAS } & \multicolumn{2}{c}{$76-77^{*}$} & \multicolumn{2}{c}{$79-80^{*}$} & \multicolumn{2}{c}{$1980^{* *}$} \\
\cline { 2 - 7 } & ha & \multicolumn{1}{c}{ Ton } & \multicolumn{1}{c}{ ha } & \multicolumn{1}{c}{ Ton } & \multicolumn{1}{c}{ ha } & Ton \\
\hline Estufas & 400 & 1000 & 798 & 1995 & 900 & - \\
\hline Túneis & 50 & 30 & 236 & 142 & 370 & \\
\hline Cobertura de solo & 360 & 117 & 2081 & 1040 & 2100 & \\
\hline TOTAL & 810 & 1147 & 3115 & 3177 & 3370 & \\
\hline
\end{tabular}

- Valores da CNP; ** Valor da APPA (').

\footnotetext{
* Publicado com o acordo de Petrovisão/CNP.
}

\begin{tabular}{|c|c|c|c|c|c|c|}
\hline & PLA & $\begin{array}{l}\text { QUAD } \\
\text { CCULTL }\end{array}$ & $\begin{array}{l}\text { RO II } \\
\text { RA EN }\end{array}$ & 1976 & & \\
\hline & POR & JGAL* & FRAN & $\mathbf{C C A}^{\star \star \star}$ & MUND & IAL $\mathbf{L}^{\star *}$ \\
\hline & ha & Ton & ha & Ton & ha & Ton \\
\hline Estufas & 400 & 1000 & 2000 & 5000 & 48000 & 140000 \\
\hline Túneis & 50 & 30 & 12500 & 8000 & 82000 & 87000 \\
\hline Cobertura de solo & 360 & 117 & 33000 & 8000 & 260000 & 63000 \\
\hline TOTAL & 810 & 1114 & 47500 & 21000 & 390000 & 290000 \\
\hline
\end{tabular}

* Valores da CNP (2); ** Valores da CdF Chimie (').

QUADRO III

EVOLUÇÃO DA PLASTICULTURA EM FRANÇA ENTRE 1975 E 1977

\begin{tabular}{lcccc}
\hline \multirow{2}{*}{ TÉCNICAS } & \multicolumn{2}{c}{$1975^{*}$} & \multicolumn{2}{c}{$1977^{* *}$} \\
\cline { 2 - 5 } & ha & Ton & ha & Ton \\
\hline Estufas & 2000 & 5000 & 2600 & 5700 \\
\hline Túneis & 12500 & 8000 & 11000 & 10350 \\
\hline Cobertura de solo & 33000 & 8000 & 35000 & 10000 \\
\hline TOTAIS & 47500 & 21000 & 48600 & 25000 \\
\hline
\end{tabular}

* Valores da CdF Chimie ('); ** Valores da CdF Chimie (").

\section{Estufas}

Assim (por exemplo), falando nas estufas na zona algarvia, estima-se a área coberta em 400 ha ou seja aproximadamente metade da área de estufas em todo o País. Até 1976, nessa região, a área correspondente era apenas de 150 ha e o desenvolvimento registou-se desde essa altura até 1979. Daí para cá a área coberta por estufas não aumentou. Apenas o poderá fazer e atingir um valor possível de 1500 ha, com a construção e entrada em funcionamento de novas barragens e sistemas de irrigação.

De acordo com o que nos foi possível averiguar, esse facto, consequência da estagnação da própria horticultura na região, é devido a três tipos de razões:

$1 .^{\circ}-$ Ao aumento excessivo da salinidade das águas de rega;

$2 .^{\circ}$ - À utilização generalizada de sistemas de rega pouco evoluídos;

$3 .^{\circ}$ - A erros de concepção de algumas exploraçð̃es, com os consequentes insucessos económicos, que terão desmotivado e desmoralizado outros agricultores interessados.

a Companhia Nacional de Petroquímica. 


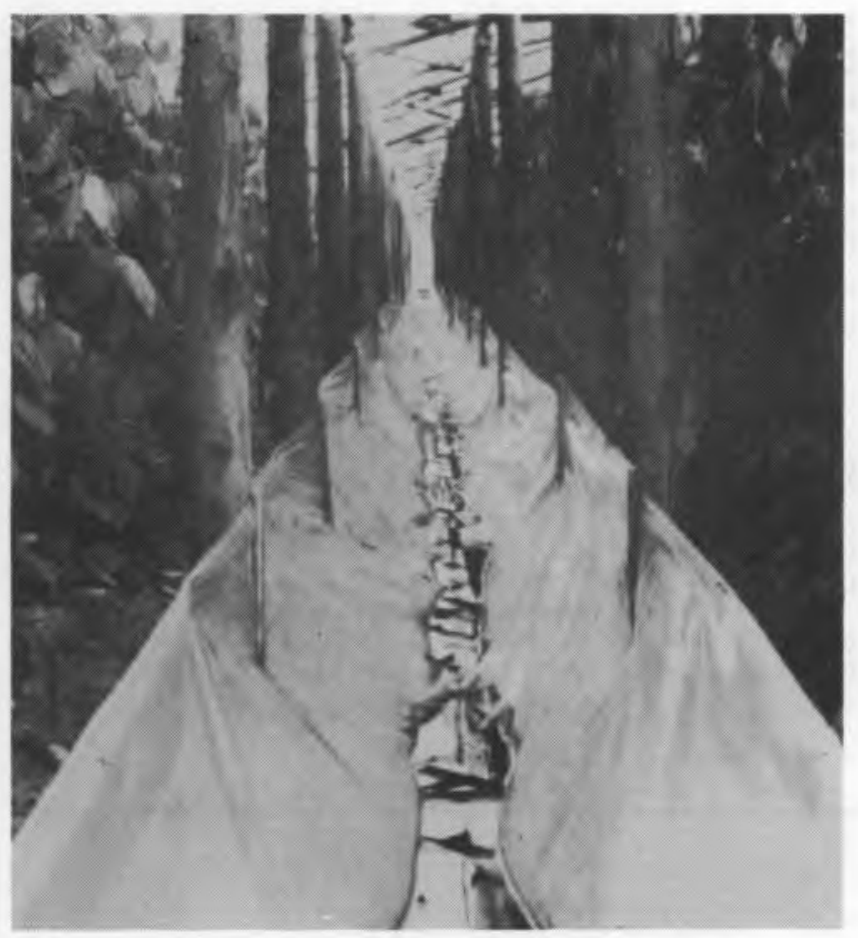

Mas nas regið̌es onde o problema da salinidade das águas de rega não se pð̃e, ou se pð̃e com menor acuidade, e onde esta técnica não está ainda suficientemente divulgada é razoável esperar um grande incremento nas culturas sob estufa.

\section{Coberturas de solos}

No tocante à cobertura de solos, parece-nos que esta técnica, que de acordo com o QUADRO I registou um enorme acréscimo entre 76 e 80 , continua a aumentar espectacularmente. Embora recorra a filmes muito menos espessos do que os utilizados nas estufas é natural que não só conserve o $1 .^{\circ}$ lugar em área abrangida mas também venha a corresponder ao maior consumo de materiais plásticos (no caso polietileno de baixa densidade).

As suas principais vantagens consistem na diminuição do período de germinação das plantas, com a consequente antecipação na data das colheitas, na grande economia em água de rega, pois o plástico retém a humidade dos solos, na maior facilidade de combate à infestação de terrenos. Finalmente possibilita a recuperação de solos não produtivos. Com a sua utilização a plasticultura deixou de estar "encerrada» em espaços limitados e invadiu os campos. Tanto se aplica a pequenas plantas como a árvores de fruto. As técnicas de cobertura de solos com plásticos e bem assim as técnicas de semeio com ela relacionadas podem ser, em muitos casos, facilmente mecanizáveis. O seu alastramento às grandes áreas é tal que constitui uma verdadeira e importantíssima revolução na produção agrícola.

\section{Túneis}

Por último falemos dos túneis, pequenos abrigos ou estufins, os quais registaram também um grande aumento de 1976 a 1980 (QUADRO I).

É possível que a sua utilização futura venha a registar acréscimos mais moderados devido às elevadas exigências em mão-de-obra que lhe estão associadas.

Em França, nomeadamente entre 1973 e 1977 registou-se um decréscimo de $15 \%$ na área destinada a esta técnica $\left({ }^{4}\right)$ a favor do aumento substancial registado nas restantes semiforçagens.

É importante referir que as várias técnicas, isto é, os diversos tipos de aplicação de plástico na construção de abrigos, de que temos vindo a falar, não são mutuamente exclusivas. Com efeito, sob uma grande estufa, podem-se ainda proteger as culturas por meio de túneis ou de coberturas de solo durante parte do ano. Este procedimente é habitualmente designado por "duplo abrigo" ou "abrigo temporário".

\section{OS DIVERSOS TIPOS DE FILMES AGRÍCOLAS}

Como é natural os filmes plásticos a utilizar terão características diferentes consoante o fim a que se destinem.

Assim, nas estufas ou grandes abrigos deseja-se que os filmes durem o mais possivel, principalmente se esse aumento de duração tiver apenas uma reduzida contrapartida nos custos. Temos então os filmes de "longa duração". Paralelamente há casos em que, para além da duração do filme, se deseja aumentar o valor das temperaturas mínimas e evitar o fenómeno conhecido por "inversão de temperatura", associado às geadas de inverno. Usam-se nestes casos filmes "térmicos" ou "infravermelhos".

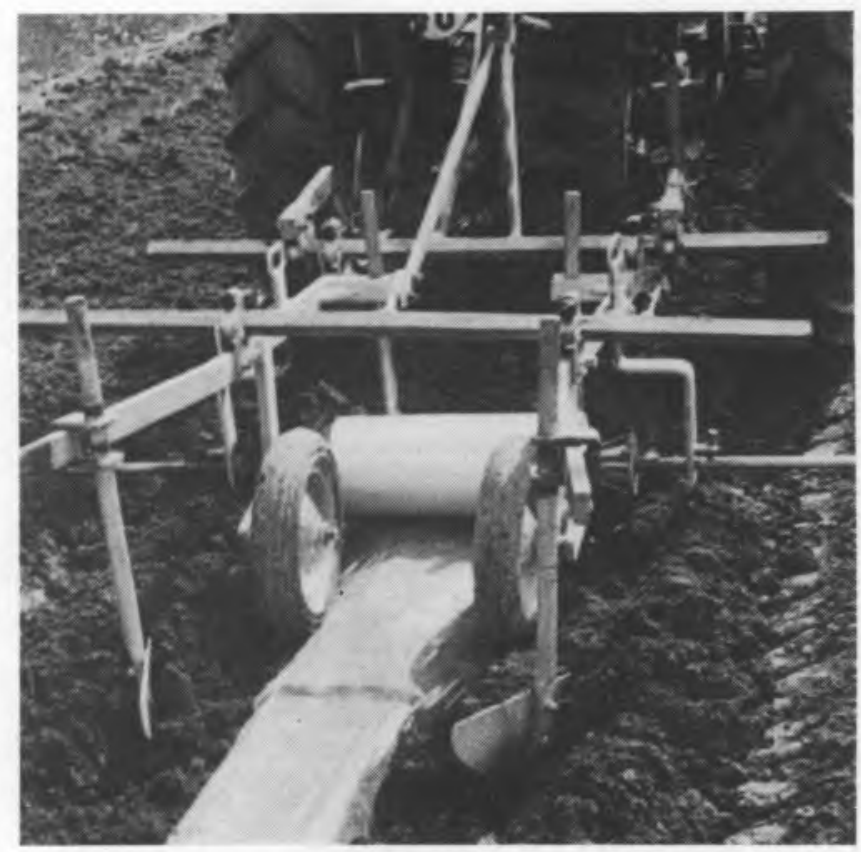

Por outro lado, nas coberturas de solos, será normal pretender que o filme, uma vez cumprida a sua tarefa, desapareça, evitando não só a laboriosa e dispendiosa recolha mas também o aspecto degradado que os plásticos, após a sua utilização correcta, transmitem aos campos. Repare-se que, a não ser em muito pequenas áreas, não é viável a recuperação, lavagem e desinfestação destes filmes para novas aplicações. Daí o interesse de filmes "fotodegradáveis" que após um período pré-estabelecido de 30,60 ou 100 dias, se desfazem em pequenas partículas que se misturam nos terrenos sem qualquer dano para estes. 


\section{A ACÇÃO DA CNP}

A Companhia Nacional de Petroquímica vem procedendo, desde há cerca de três anos, a estudos que permitem determinar as melhores soluçø̃es para os problemas que, de um modo muito breve, temos vindo a expor. Com estes objectivos tem-se procedido tanto a ensaios de campo, como a experiências em laboratório. Esta tarefa é tanto mais importante, quanto é certo que a Plasticultura já não é uma técnica ou conjunto de técnicas destinadas simplesmente a ajudar o agricultor a melhorar as suas produçð̋es. De facto, essas produçð̃es aumentaram de tal forma nas zonas onde o uso correcto de plásticos se tornou habitual, que o seu hipotético abandono, ou mesmo simples regressão, teria consequências dramáticas e mesmo catastróficas sobre o custo de vida e o normal abastecimento das populaçø̄es.
$\mathrm{Na}$ verdade a Plasticultura, desde que tecnicamente bem aplicada e apoiada, é porventura uma das mais importantes contribuiçðes para o combate ao problema da fome.

No nosso caso particular, dado que o grande problema que aflige a economia portuguesa tem sido precisamente a incapacidade de atingir a desejada auto-suficiência em produtos alimentares, torna-se evidente a razão do nosso interesse e a medida do nosso empenhamento.

\section{BIBLIOGRAFIA}

(1) CdF Chimie, Information $\mathrm{n} .^{\circ} 2$.

(2) A. Santos Costa, "A Utilização de Plásticos na Agricultura" CNP - Boletim Informativo. Suplemento.

(3) APPA, Relatório e Contas 1980.

(4) "La Plasticulture", CdF Chimie, 2. a Edição 1978. 